\title{
Development of Silica-Based Monoliths for the Capture of $\mathrm{CO}_{2}$
}

\author{
Andressa Aparecida Alves ${ }^{a}{ }^{\oplus}$, Jéssica de Oliveira Notório Ribeiro ${ }^{a}{ }^{\oplus}$, Wander Luiz Vasconcelos ${ }^{b}$ \\ ${ }^{a}$ Departamento de Engenharia Quimica, Universidade Federal de Minas Gerais, Belo Horizonte, MG, Brasil \\ ${ }^{b}$ Departamento de Engenharia de Metalúrgica e de Materiais, Universidade Federal de Minas Gerais, \\ Belo Horizonte, $M G$, Brasil
}

Received: April 08, 2019; Revised: August 01, 2019; Accepted: August 05, 2019

\begin{abstract}
The synthesis of mesoporous materials in macroscopic scale, as for example, the monoliths, has been of great interest in view of the wide range of applications that this material holds. Thus, this work consists of the production of silica monoliths for the purpose of they being used in the carbon dioxide $\left(\mathrm{CO}_{2}\right)$ adsorption process. The adsorbents were prepared in pure form and also with addition of heteroatoms: $\mathrm{Al}, \mathrm{Ti}$ and $\mathrm{Zr}$. The samples were then functionalized with pentaethylenehexamine (PEHA) by the wet impregnation method. The materials were characterized by the following techniques: X-ray diffraction (XRD), textural analysis, Fourier transform infrared spectroscopy (FTIR), Scanning electron microscopy (SEM) and Thermogravimetry (TG/DTG). The analyses indicated that the materials synthesized with heteroatom incorporation presented a disordered pore structure and high surface area $\left(1387 \mathrm{~m}^{2} / \mathrm{g}\right.$ for sample Ti/M1). In addition, they showed a significant increase in adsorption of $\mathrm{CO}_{2}$ relative to their parent sample, a fact that is not much explored in the literature. The $\mathrm{CO}_{2}$ adsorption performance tests were carried out at $30^{\circ} \mathrm{C}$ and atmospheric pressure. All functionalized materials demonstrated improved $\mathrm{CO}_{2}$ adsorption capacity relative to their starting samples. Adsorption capacities up to $111.3 \mathrm{mg} / \mathrm{g}$ were found in this work, which makes the materials developed promising candidates for the capture of $\mathrm{CO}_{2}$.
\end{abstract}

Keywords: Adsorption, sol-gel, silica monolith, metals, functionalization.

\section{Introduction}

According to the IPCC ${ }^{1}$, the carbon capture and storage (CCS) technology is one of the options, among the mitigation actions, that most contributes to the equilibrium of the levels of anthropogenic greenhouse gases in the atmosphere. A plant with CCS could reduce $80-90 \%$ of $\mathrm{CO}_{2}$ emissions from a plant that does not have this system ${ }^{1}$. The CCS is subdivided into three phases: the capture, transport and storage of $\mathrm{CO}_{2}{ }^{2}$.

For the purpose of using the CCS process it is necessary to employ $\mathrm{CO}_{2}$ separation techniques, such as absorption, separation by membranes, cryogenic distillation, adsorption, among others ${ }^{3-5}$. The most used technique currently in the separation of $\mathrm{CO}_{2}$ from a gas mixture is the absorption using amines. However, although it is effective for its purpose, it presents some disadvantages due to the high energy cost for solution regeneration and oxidative degradation ${ }^{6,7}$. As a way to minimize these problems, the adsorption technique appears in this context as a promising alternative. The use of solid adsorbents has been highlighted for several reasons, namely: smaller energy consumption, easy regeneration, less amount of waste produced and high separation rate $\mathrm{e}^{3,5,7,8}$.

Different adsorbent materials are currently under study for the $\mathrm{CO}_{2}$ capture process, among them are mesoporous silicas ${ }^{9}$. This material can be synthesized in the form of powders ${ }^{10,11}$, films ${ }^{12,13}$, fibers ${ }^{14,15}$ and monoliths ${ }^{16,17,26,27,18-25}$.
Mesoporous silica is usually produced in the form of fine powders, and when synthesized in this way, a conformation step must often be included during processing for most applications. The conformation process in this case is a further stage in the processing and thus increases production costs and complexities. Moreover, it may also lead to significant loss in porosities if high temperatures are necessary to ensure enough mechanical resistance of the final pellets. The advantage of synthesizing the mesoporous silica in monolith form is that the conformation step is not necessary. It is possible to synthesize the material in the desired form, because the shape of the mold in which the monolith is produced is maintained ${ }^{16,23,27-30}$. Therefore, the materials manufactured as monoliths may save time and reduce production costs, as well as overcome the problem of loss of porosity present in the materials in the form of fine powders.

It should be emphasized that the research on the incorporation of heteroatoms in silica-based materials has shown to be very effective in obtaining materials with high thermal stability and regenerability ${ }^{31-34}$. This modification technique is employed to improve, in addition to the mentioned characteristics, the properties of $\mathrm{CO}_{2}$ adsorption ${ }^{7,934,35}$. However, it was observed that the number of scientific publications regarding the study of the evaluation of $\mathrm{CO}_{2}$ adsorption performance for materials incorporated with heteroatoms, similar to those synthesized in this work, is extremely low ${ }^{31-34}$. 
This scarcity can be justified by the fact that the works found in the literature on the incorporation of heteroatoms do not perform this procedure with the purpose of contributing directly with the increase of the $\mathrm{CO}_{2}$ adsorption capacity, since the materials obtained from that are not analyzed in $\mathrm{CO}_{2}$ capture applications. Nevertheless, in this work the materials incorporated with heteroatoms were submitted to the performance evaluation test, in contrast to what is most often found in the literature.

In this work the synthesis of a series of silica monoliths was carried out and these samples were prepared with and without addition of heteroatoms: Al, Ti and Zr. Subsequently, the obtained materials were functionalized with PEHA. These procedures were performed with the objective of obtaining a material with high $\mathrm{CO}_{2}$ adsorption capacity. The silica monoliths were prepared by sol-gel process, for the purpose of being applied in the treatment of several gas streams, for example, in biogas, landfill gas and sewage, etc ${ }^{36}$. The materials were characterized by the following techniques: XRD, textural analysis, FTIR, SEM and TG/DTG.

\section{Experimental}

\subsection{Silica monolith synthesis}

Monolith M1 was prepared using tetraethoxysilane (TEOS) as a silica source and the cetyltrimethylammonium bromide (CTAB) as surfactant. The methodology for the preparation of this sample was based on the literature ${ }^{37}$. The experimental procedure consisted of adding ethyl alcohol to the aqueous nitric acid solution. Then, the polyethylene glycol (PEG) was dissolved in that solution and when a homogeneous solution was obtained, the TEOS was added. Thereafter, the sol formed was stirred until a clear solution was obtained. The CTAB was added and stirring continued until the surfactant was completely dissolved. The final sol molar composition was 1 TEOS: 0.19 CTAB: $0.25 \mathrm{HNO}_{3}$ : 0.26 PEG: $2 \mathrm{C}_{2} \mathrm{H}_{5} \mathrm{OH}: 14.69 \mathrm{H}_{2} 0$. The sample was placed in the oven at $60{ }^{\circ} \mathrm{C}$. The gelling time was also observed and the sample remained in the oven for another $48 \mathrm{~h}$. The removal of the surfactant was performed through a thermal treatment. The material was heated up to $550{ }^{\circ} \mathrm{C}$ at $1^{\circ} \mathrm{C} / \mathrm{min}$, and kept at this temperature for $6 \mathrm{~h}$. Cooling was carried out at a rate of $10^{\circ} \mathrm{C} / \mathrm{min}$ to room temperature. The steps involved in the preparation of material M1 can be seen in Fig. 1.

\subsection{Synthesis of monoliths incorporated with heteroatoms}

The insertion of the heteroatoms was performed during the synthesis of the monolith by two processes: addition of metal salt after addition of the surfactant and incorporation of alkoxides of metals after the addition of the silica source and the surfactant. The addition was performed using the following precursors: aluminum sulfate, titanium (IV) butoxide and zirconium (IV) propoxide, and the synthesized materials were named: $\mathrm{Al} / \mathrm{M} 1$, $\mathrm{Ti} / \mathrm{M} 1$ and $\mathrm{Zr} / \mathrm{M} 1$, respectively. The procedure for preparing the monoliths was performed with the addition of $10 \mathrm{~mol} \%$ of metal.

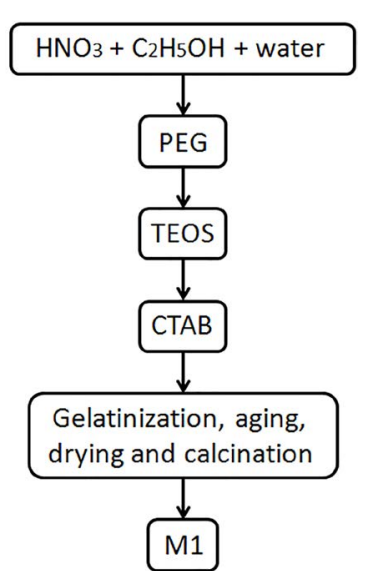

Figure 1. Steps involved in the preparation of silica monolith M1.

\subsection{Functionalization of monoliths}

The adsorbent material was impregnated to obtain loading of $25 \mathrm{wt} \%$ of PEHA. Samples loaded with the amine were identified as: Al/M1-P, Ti/M1-P and Zr/M1-P. The procedure for the impregnation of amines in the porous support consisted in initially dissolving PEHA in ethanol under stirring. Soon after the complete dissolution, the calcined material was enveloped on filter paper and added to the amine solution with ethanol and stirred for about 24 hours. Thereafter, the solvent on the adsorbent was evaporated in the oven at a temperature of $60^{\circ} \mathrm{C}$. The schematic diagram of the procedures for obtaining adsorbents impregnated with amine can be seen in Fig. 2.

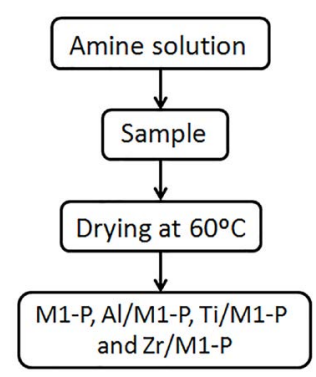

Figure 2. Schematic diagram of the procedures for obtaining adsorbents impregnated with amine.

\subsection{Characterization of silica monoliths}

The XRD was carried out using a PANalytical Empyrean $\mathrm{X}$-ray diffractometer. The samples were initially powdered to perform the XRD analysis. The diffractograms were taken in the $2 \theta$ range from $0.41^{\circ}$ to $3.99^{\circ}$, using scan speed of $0.02^{\circ}$ with an acquisition time of $20 \mathrm{~s}$ per step. The analysis XRD was carried out to verify that the samples had ordering pores. To determine the specific surface area, pore volume and pore diameter of the samples, the equipment used was a Quantachrome Autosorb-1. The samples were treated under vacuum at $130{ }^{\circ} \mathrm{C}$ prior to analysis. The samples were examined in a Perkin-Elmer Frontier spectrometer. 
The samples, prepared as pellets with $\mathrm{KBr}$, were analyzed in the range of wavenumbers from $4000 \mathrm{~cm}^{-1}$ to $400 \mathrm{~cm}^{-1}$. To perform the analysis on the SEM, the samples were powdered and their surfaces were covered with a layer of about $15 \mathrm{~nm}$ of amorphous carbon to improve surface conductivity, avoiding the accumulation of charges during image acquisition. SEM was performed using a Quanta 3D FEG FEI microscope. The energy dispersive X-ray spectrometry (EDS) experiment was performed using acceleration voltage of $15 \mathrm{kV}$, size 6.5 and opening of $50 \mathrm{~mm}$.

The thermogravimetric analysis was performed using a Perkin-Elmer STA 6000 simultaneous thermal analyzer. The materials were heated from $30{ }^{\circ} \mathrm{C}$ to $800{ }^{\circ} \mathrm{C}$ at a rate of $10{ }^{\circ} \mathrm{C} / \mathrm{min}$. The tests used a Ni flow of $20 \mathrm{~mL} / \mathrm{min}$. The amine content of the samples was determined in $\mathrm{mmol} / \mathrm{g}$ through Equation 138,39 .

$$
N=\frac{\% m_{\text {loss }}}{100} \cdot \frac{1000}{M M_{l i g}}
$$

Where refers to the mass loss in TG in the temperature range corresponding to the decomposition of the amine PEHA and is the molecular weight of the organic part of the amine which was burned during heating. It was considered that the is the molecular weight of the amine PEHA, i.e., the value used was $232.38 \mathrm{~g} / \mathrm{mol}$.

The $\mathrm{CO}_{2}$ adsorption performance tests were carried out with a Perkin-Elemer STA-6000 thermobalance. The samples were initially cleaned in a thermal treatment at $110^{\circ} \mathrm{C}$ for $10 \mathrm{~min}$, under He flow. Subsequently, the system was cooled to a temperature of $30^{\circ} \mathrm{C}$ and the $\mathrm{CO}_{2}$ adsorption step was performed. The adsorption process was carried out at atmospheric pressure, under gas flow of $50 \mathrm{~mL} / \mathrm{min}$ at $30^{\circ} \mathrm{C}$ for 40 min with $\mathrm{He}$ as purge gas.

\section{Results and Discussion}

\subsection{Characterization of pure silica monoliths and incorporated with heteroatoms}

\subsubsection{XRD}

The small angle X-ray diffractograms of the pure calcined samples and incorporated with heteroatoms were obtained by XRD analysis (not shown). The XRD analyses showed that all samples presented a similar structure, without having ordered pores.

\subsubsection{FTIR}

The spectra obtained for the samples are shown in Fig. 3. For all the studied materials, it is possible to observe a broad band around $3470 \mathrm{~cm}^{-1}$ relative to the hydroxyl groups of silanol terminations and water adsorbed on the surface of the material ${ }^{3,40,41}$. The band at approximately $1640 \mathrm{~cm}^{-1}$ refers to the adsorbed water 3,40,41.
The absorption bands in regions close to $1095 \mathrm{~cm}^{-1}, 800$ $\mathrm{cm}^{-1}$ and $465 \mathrm{~cm}^{-1}$ are attributed to vibrations $v_{\text {as }}(\mathrm{Si}-\mathrm{O}-\mathrm{Si})$, $v_{\mathrm{s}}(\mathrm{Si}-\mathrm{O}-\mathrm{Si})$ and $\delta(\mathrm{Si}-\mathrm{O}-\mathrm{Si})$, respectively ${ }^{42}$. The absorption band around $965 \mathrm{~cm}^{-1}$ can be associated with the vibration of the $\mathrm{Si}-\mathrm{OH}$ or $\mathrm{Si}^{-} \mathrm{O}^{-3,40,41,43}$.

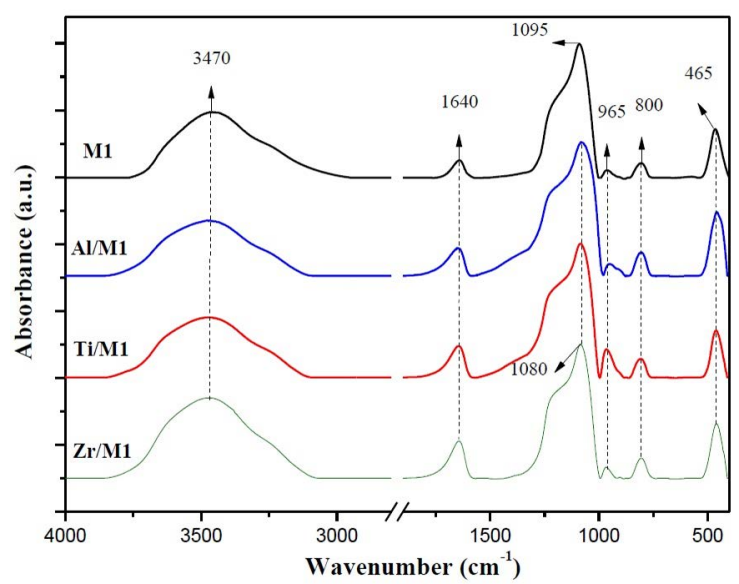

Figure 3. FTIR spectra for pure M1 calcined materials and incorporated with heteroatoms.

It can be seen the bands in the regions of $1095 \mathrm{~cm}^{-1}$ and $800 \mathrm{~cm}^{-1}$ present in the spectrum of the starting sample were shifted to $1080 \mathrm{~cm}^{-1}$ and $802 \mathrm{~cm}^{-1}$ in the spectrum of the Al/M1. A similar result was reported by Xie et al. ${ }^{44}$. They also observed displacements in these regions of the spectrum, and suggested that these changes may have been due to the formation of the Al-MCM-41 structure. The displacement in the region close to $1080 \mathrm{~cm}^{-1}$ may have appeared in the spectrum of the aluminum-containing material still due to the simultaneous vibrations of the $\mathrm{SiO}_{4}$ and $\mathrm{AlO}_{4}$ tetrahedra ${ }^{45}$. This behavior was also verified for the samples incorporated with $\mathrm{Ti}$ and $\mathrm{Zr}$. Since the decrease in the wavenumber of the absorption signal in the spectrum indicates an increase in the length of the bonds related to it (or decrease in the strength of these bonds), one may also conclude that the Si-O-Si framework was disturbed in these materials when compared to their pure silica version. Therefore, this suggests a successful insertion of the metals into the silica monolith

\subsubsection{Textural analysis}

The textural characteristics of the pure calcined materials and with addition of heteroatoms were determined through the nitrogen adsorption/desorption isotherms presented in Fig. 4. It is also possible to observe the pore distribution of the samples in Fig. 5.

The samples synthesized in this work have the shape of the isotherms with intermediate characteristics between types I and IV, according to IUPAC recommendations ${ }^{46}$. However, they can not be classified in this way because the adsorptions branches do not exhibit the typical inflexion. 


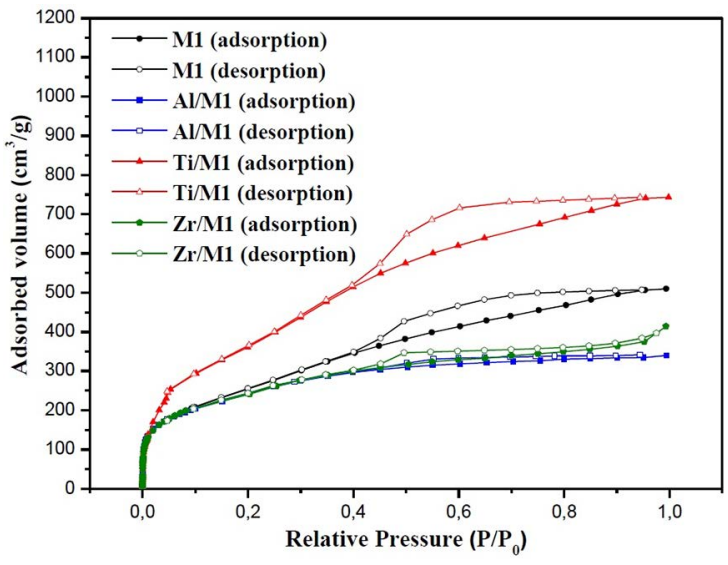

Figure 4. $\mathrm{N}_{2}$ adsorption-desorption isotherms of the samples M1, $\mathrm{Al} / \mathrm{M} 1, \mathrm{Ti} / \mathrm{M} 1$ and $\mathrm{Zr} / \mathrm{M} 1$.

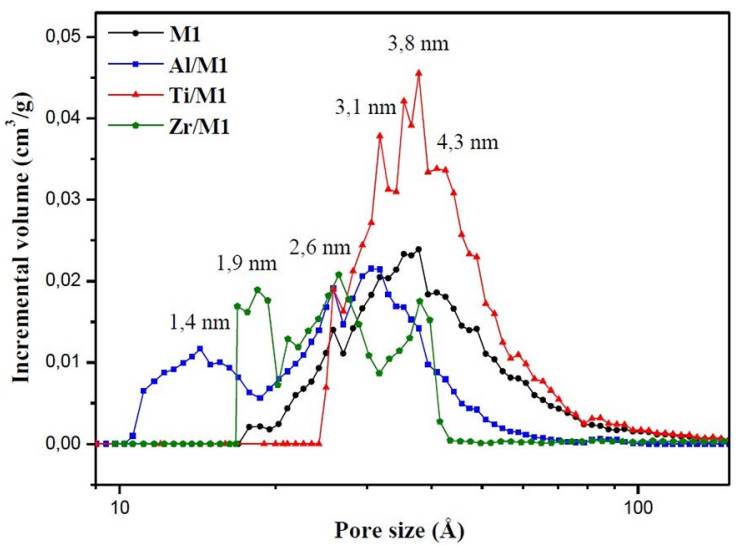

Figure 5. Pore distribution curves of the samples M1, A1/M1, $\mathrm{Ti} / \mathrm{M} 1$ and Zr/M1.

As can be seen in the isotherms presented in Fig. 4, it was possible to verify that along the desorption branch in the $\mathrm{P} / \mathrm{P}_{0}$ range $0.4-0.45$ (for $\mathrm{N}_{2}$ at $77 \mathrm{~K}$ ) all the samples presented a forced closure of the hysteresis loop, which can be explained by the tensile strength effect (TSE) ${ }^{47-49}$. In the pores with critical diameters smaller than $4 \mathrm{~nm}$, the disappearance of the hysteresis occurs when there is a collapse of the hemispherical meniscus and the interconnected pores filled with $\mathrm{N}_{2}$ are immediately emptied ${ }^{47,49}$. Due to this sudden drop in volume adsorbed during desorption, the mentioned forced closure occurs in the mentioned critical pressure range ${ }^{47,49}$. The tensile strength in the adsorbed phase increases as the pore size decreases because of the meniscus instability due to the increased chemical potential of the pore walls ${ }^{47}$.
The TSE observed on the form of the isotherms is explained by the presence of narrowed and blocked mesopores through micropores ${ }^{50}$. As a result, it is possible to observe a peak that is not real between 3.5 and $4.0 \mathrm{~nm}$ in the pore size distribution (Fig. 5), which can be called an artefact ${ }^{49,50}$.

Fig. 5 shows the pore distribution curves for the sample M1, pure and incorporated with heteroatoms. From this figure it is possible to observe that the samples have the great majority of pores with the size greater than $2 \mathrm{~nm}$, so these materials are mesoporous, according to IUPAC classification ${ }^{46}$. However, these mesopores are blocked as previously explained.

Through the textural analysis, it was possible to determine the estimated surface area and pore volume for each material, according to Table 1. It can be seen that besides the silica monolith, the samples can be compared with the MCM-41 material because of their similar surface area and range of mesopore sizes. However, the synthesized samples do not present organized pores as MCM-41. This similarity of textural features between the samples from this work and MCM-41 is expected because they share a common porogenic agent: the CTAB. The parameters for the studied materials are in agreement with the values reported in the literature for the silica-based monolith, an example is the monolith obtained by Chen et al. ${ }^{37}$, which has a surface area of $950 \mathrm{~m}^{2} / \mathrm{g}$, and with MCM-41 material, because the values found in the scientific works for surface area and pore volume vary from $669 \mathrm{~m}^{2} / \mathrm{g}^{51}$ to $1031 \mathrm{~m}^{2} / \mathrm{g}^{52}$ and $0.2 \mathrm{~cm}^{3} / \mathrm{g}^{40}$ to $0.9 \mathrm{~cm}^{3} / \mathrm{g}^{52}$, respectively. The performances of the materials MCM-41 and the monoliths synthesized in this work can be compared due to the similarities in these materials, as previously mentioned. This comparison is made in the following sections.

It is possible to observe that after the addition of the heteroatoms, all the materials obtained presented a change in their textural properties. It should be emphasized that all samples synthesized with addition of heteroatoms may exhibit pores with wide distribution of shapes and diameters because such materials have a disordered pore distribution, as confirmed by analyses.

\subsubsection{SEM}

The SEM analysis of monoliths with addition of heteroatoms (Al, Ti and $\mathrm{Zr}$ ) can be seen in Fig. 6. From this figure, it is possible to observe representative fragments of the samples studied. Analyzing the Ti/M1 and $\mathrm{Zr} / \mathrm{M} 1$ micrographs, the samples showed a structure consisting of particles that appear to be generally irregular.

Table 1. Textural properties and $\mathrm{CO}_{2}$ adsorption capacity of samples.

\begin{tabular}{|c|c|c|c|c|c|c|c|c|}
\hline \multirow{2}{*}{ Monolith } & \multirow{2}{*}{$\%$ metal } & \multicolumn{3}{|c|}{ without PEHA } & \multicolumn{4}{|c|}{ With PEHA } \\
\hline & & $A\left(m^{2} / g\right)$ & $\mathrm{V}\left(\mathrm{cm}^{3} / \mathrm{g}\right)$ & Cap. (mg/g) & $A\left(m^{2} / g\right)$ & $V\left(\mathrm{~cm}^{3} / \mathrm{g}\right)$ & Amine content (mmol/g) & Cap. (mg/g) \\
\hline M1 & - & 949.0 & 0.8 & 5.7 & 104.6 & 0.22 & 0.74 & 23.6 \\
\hline Al/M1 & 8.6 & 864.0 & 0.6 & 10.5 & 194.7 & 0.19 & 0.69 & 36.7 \\
\hline Ti/M1 & 9.6 & 1387.0 & 1.1 & 7.3 & 118.8 & 0.27 & 1.00 & 56.9 \\
\hline Zr/M1 & 6.0 & 872.0 & 0.6 & 18.3 & 139.5 & 0.25 & 0.77 & 43.6 \\
\hline
\end{tabular}




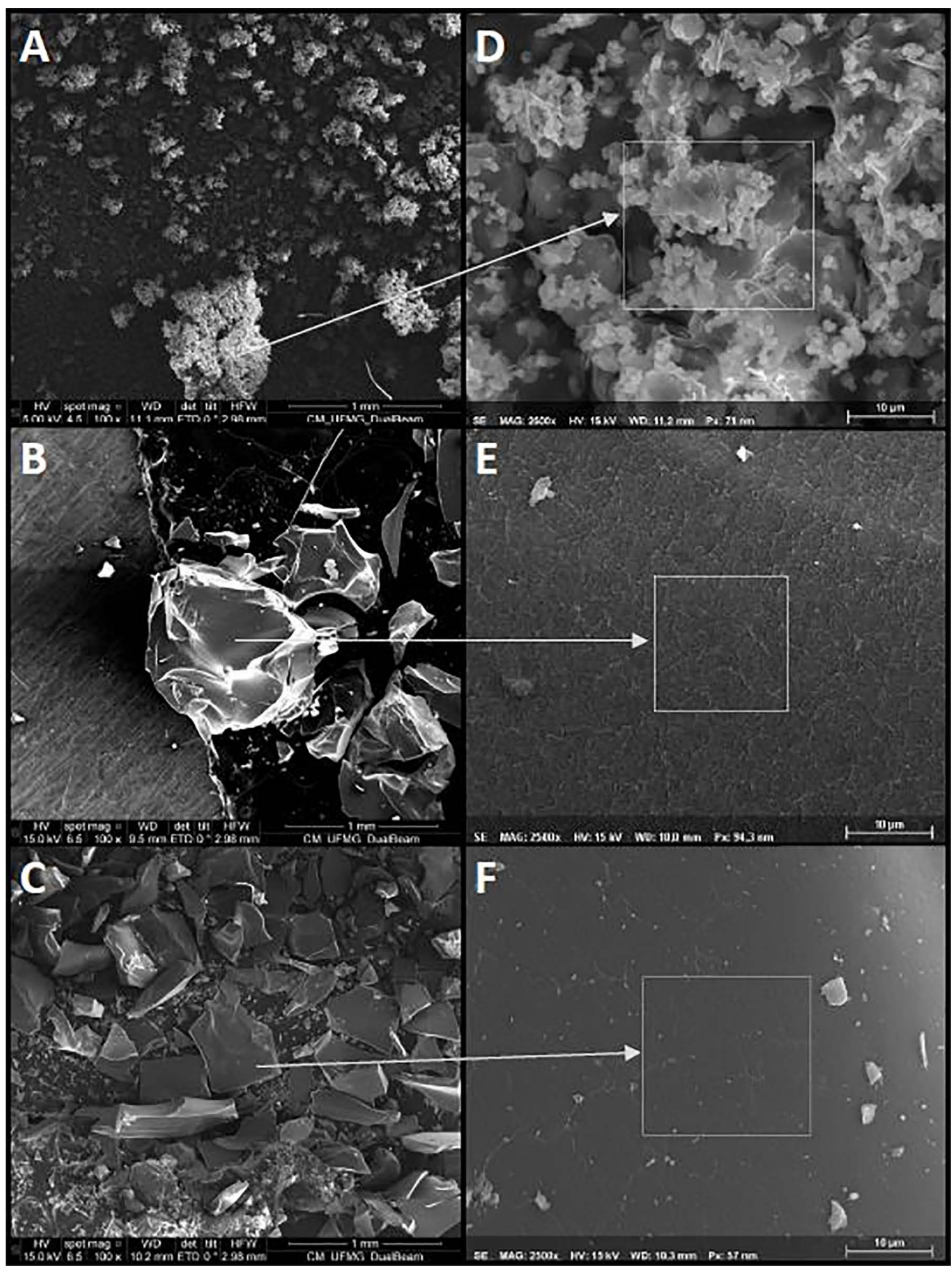

Figure 6. Scanning electron microscopy of samples Al/M1 (A), Ti/M1 (B), Zr/M1 (C), and selected region (D), (E) and (F) for the EDS technique fof samples (A), (B) and (C), respectively. 
With respect to the surface characteristics of the particles, the presence of mostly smooth surfaces is noticeable, but there are also regions that have roughness, presenting small grains, as can be seen in the figures. It is also verified the existence of some cracks in the samples surface, which probably came from the maceration process performed before the samples were analyzed in the SEM. From the observation of the micrograph of the sample Al/M1, it can be verified that, unlike the other samples, it is formed by agglomerations of rounded particles that do not have a uniform size, being noticeable the presence of small particles, of less than 3 $\mathrm{mm}$, and larger than $10 \mathrm{~mm}$. The morphology presented by these samples has good agreement with that of material AlMCM-41, as reported in works found in the literature ${ }^{40,53,54}$.

In order to estimate the values of percentages of metals present in the samples, the EDS technique was used, the percentages found for the samples can be seen in Table 1. Measurements were made in the demarcated region in Fig. 6 for each material. The percentage values found for each metal in sample M1, in which aluminum sulphate and titanium (IV) butoxide were added, were close to the amount of metal initially introduced into the samples during the synthesis, i.e, $10 \mathrm{~mol} \%$ of metal. In addition, it should be noted that the $\mathrm{Zr} / \mathrm{M} 1$ sample had a percentage of metal below what was added in the sample. The EDS analysis confirmed the presence of the metal heteroatoms in the composition of the chemical elements present in the samples, ratifying the results obtained by the FTIR analysis.

\subsubsection{Performance evaluation}

The adsorption-desorption cycles were constructed for the sample M1, pure and incorporated with heteroatoms, at 30 ${ }^{\circ} \mathrm{C}$ and $1 \mathrm{~atm}$, according to Fig. 7. From these cycles it was possible to evaluate the $\mathrm{CO}_{2}$ adsorption performance of the samples. As can be seen in the figure, the materials exhibited rapid adsorption kinetics. Note that the $\mathrm{Zr} / \mathrm{M} 1$ sample showed the steepest slope in comparison with the other samples, thus suggesting that this sample has the highest adsorption rate, which reverberates at a relatively better adsorption performance.

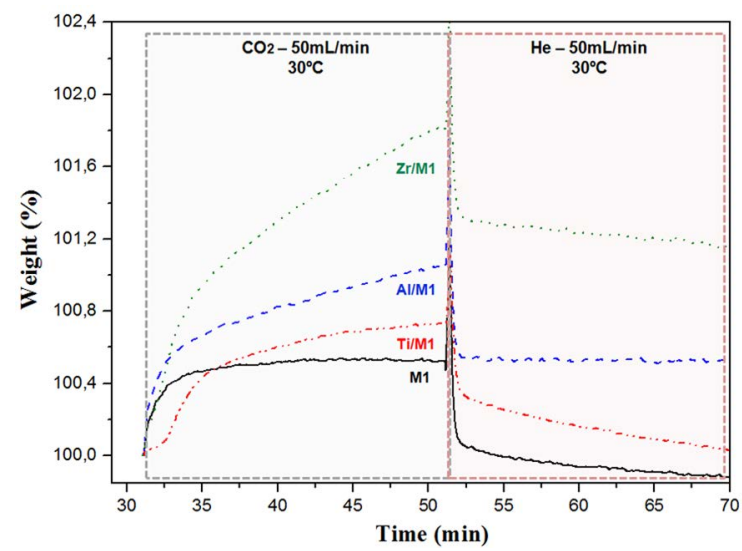

Figure 7. $\mathrm{CO}_{2}$ adsorption cycles of samples $\mathrm{M} 1$ before and after the incorporation of heteroatoms ( $\mathrm{Al}, \mathrm{Ti}$ and $\mathrm{Zr}$ ).
From these graphs it was possible to determine the $\mathrm{CO}_{2}$ adsorption capacity of the samples, as can be seen in Table 1 . It was observed that the samples incorporated with heteroatoms presented an improvement of the $\mathrm{CO}_{2}$ adsorption capacity. The materials $\mathrm{Zr} / \mathrm{M} 1$ e Al/M1 had the highest values of $\mathrm{CO}_{2}$ adsorption capacity among the other samples, with $\mathrm{Al} / \mathrm{M} 1$ almost doubling the adsorption capacity of M1 and $\mathrm{Zr} / \mathrm{M} 1$ tripling the value obtained for M1. Moreover, as the inclination of the adsorption curves in the end of the adsorption step showed, the adsorbents were not yet saturated when the desorption step began - with a longer adsorption time, an even higher capacity can be obtained.

The material $\mathrm{Zr} / \mathrm{M} 1$ had an increase in adsorption capacity of $220 \%$ only with the metal insertion, which means that the materials presented significant increases before the amine functionalization process. Additionally, it can be further stated that in applications where the use of the amine is not suitable, only the heteroatom insertion can already improve the performance of the resulting material. The study by $\mathrm{Xu}$ et al. ${ }^{31}$ was one of the few papers available reporting the value of the $\mathrm{CO}_{2}$ adsorption capacity for the Al-incorporated material MCM-41. It was possible to deduce that the results obtained in this study are in good agreement with the value found in their study, which was $7.6 \mathrm{mg} / \mathrm{g}$. As will be further discussed later in this work, it is believed that the presence of the heteroatoms created amphoteric sites on the surface of the materials, which are capable of attracting more strongly the $\mathrm{CO}_{2}$ molecules than the sites present in the pure silica. This explains the increase in adsorption capacities observed in this work for the metal-containing monoliths.

\subsection{Functionalization of silica-based monoliths}

\subsubsection{FTIR}

The FTIR was used in this stage of the work to identify the functional groups in the samples impregnated with amine in order to confirm the presence of groups characteristic of the amines used in this work. Fig. 8 shows the spectra of samples M1 without and with addition of metal heteroatoms functionalized with PEHA. In this figure are noticed the bands in the same regions present in the spectrum of the starting sample.

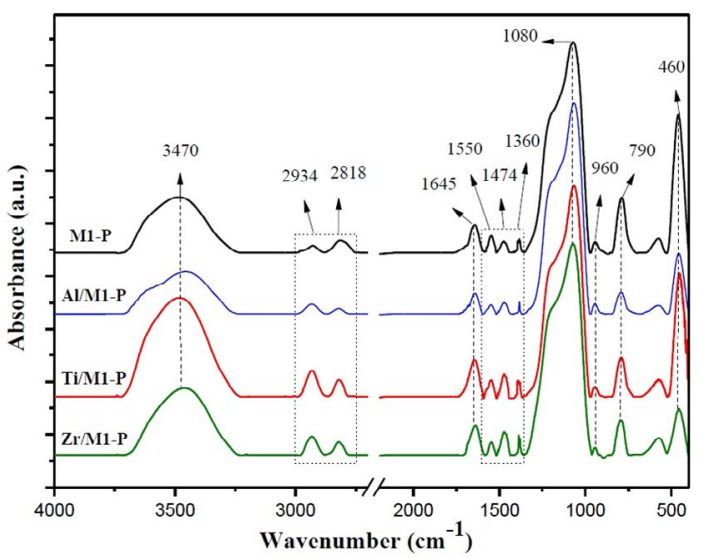

Figure 8. FTIR spectra of PEHA-functionalized samples. 
As can be seen in all the spectra present in Fig. 8, there is a diminution of the band near the $960 \mathrm{~cm}^{-1}$ region, a fact that can be justified due to the interaction between the surface $\mathrm{Si}-\mathrm{OH}$ groups and the molecules PEHA. Ji et al. ${ }^{55}$ also obtained a decrease in the intensity of the absorption band designated for vibrations of the $\mathrm{Si}-\mathrm{OH}$ group on the porous silica material supported with PEHA.

It is also possible to observe for all samples the appearance of bands, namely: the band around $1360 \mathrm{~cm}^{-1}$ that is associated with vibration $\delta(\mathrm{C}-\mathrm{N})^{42}$, the band of $1474 \mathrm{~cm}^{-1}$ that can be attributed to symmetrical flexion of amines $\left(-\mathrm{NH}_{2}\right)^{55}$, and the band of $1550 \mathrm{~cm}^{-1}$, which refers to the $\delta(\mathrm{N}-\mathrm{H})$ of $-\mathrm{NH}^{-42}$. The presence of these peaks was also described by Liu et al. ${ }^{42}$, who synthesized the material MCM-41 impregnated with PEHA and Ji et al. ${ }^{55}$, which have developed a porous silica material supported with PEHA. This is an indication that the material was successfully functionalized.

Two other absorption bands, $2818 \mathrm{~cm}^{-1}$ and $2934 \mathrm{~cm}^{-1}$, were also identified which refer to the symmetrical and asymmetric stretches of $\mathrm{CH}_{2}$, respectively. The presence of these bands suggests that the amine PEHA was introduced into the material and have also been reported by ${ }^{42,55,56}$. It is visible from the figures that Ti/M1-P has more pronounced bands referring to the amine group, thus indicating that this sample has higher amine content than the other samples.

\subsubsection{Textural analysis}

Through the textural analysis, the isotherms and pore size distribution curves were obtained for all PEHA-functionalized samples. The isotherms of the samples M1 before and after incorporation of the heteroatoms impregnated with PEHA can be seen in Fig. 9, as well as their respective pore distribution curves in Fig. 10. It is verified in the figures that after the functionalization of the samples there was a great change in the adsorption-desorption isotherms and in the pore distribution of all the materials studied. It is important to point out that the changes are reflections of the modifications resulting from the functionalization process.

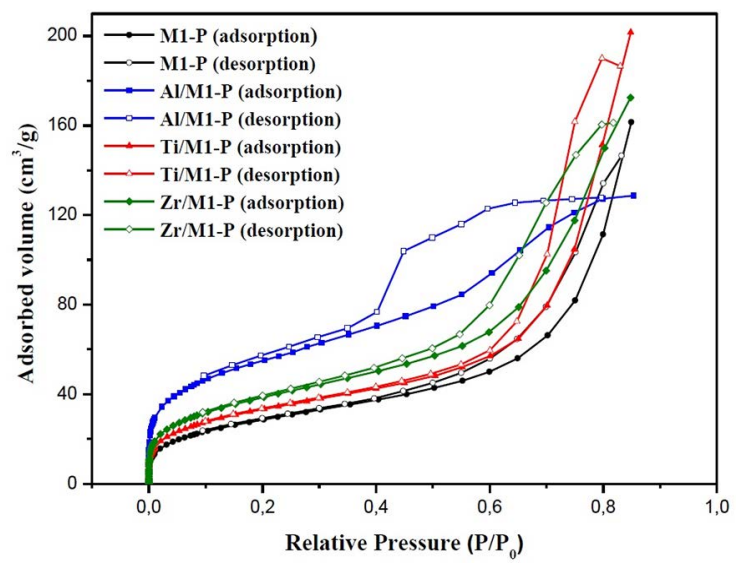

Figure 9. Nitrogen adsorption-desorption isotherms for the samples M1 incorporated with heteroatoms and functionalized with PEHA.

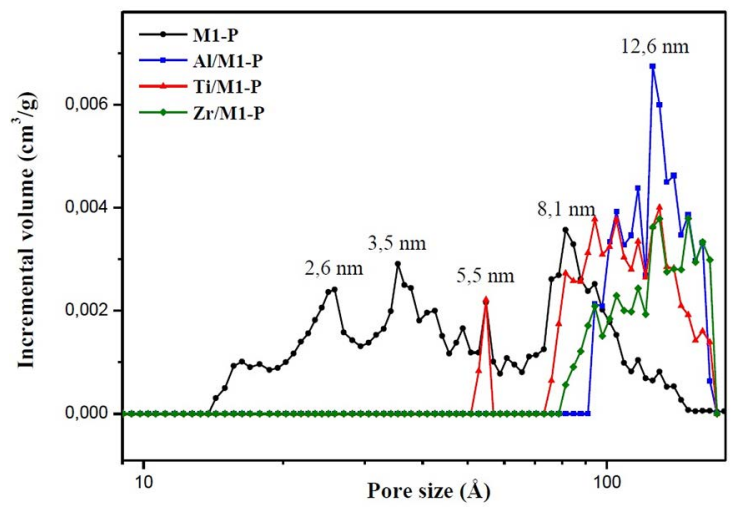

Figure 10. Pore distribution curves for the samples M1 incorporated with heteroatoms and functionalized with PEHA.

The majority of the PEHA-functionalized samples presented intermediate characteristics between the isotherms type I and IV, typical isotherms of microporous and mesoporous materials, respectively, according to IUPAC ${ }^{46}$. However, as explained in section 3.1.3, they can not be classified in this way due to TSE.

Table 1 presents the textural properties of the functionalized samples, determined from the textural analysis. According to the data obtained, it can be ascertained that the parameters of the samples decreased substantially after the functionalization step, relative to the materials before impregnation. This behavior has good agreement with the works described in the literature ${ }^{8,57,58}$.

A significant reduction in surface areas and pore volumes may be related to the functionalization process, in which the amines probably have filled the pores and also must have been deposited on the surface of the materials ${ }^{31,34,52,59}$. This behavior also occurred in the work of Carvalho et al. ${ }^{60}$, in which the authors report that the reduction of the surface area and pore volume of the materials MCM-41, after the functionalization process, may indicate that the pores were filled or a new structure formed with the amine groups aggregated on the surface of the materials. This result is consistent with the results obtained by the FTIR method and confirms that the impregnation of amines in the materials occurred successfully. By comparing the samples before and after the functionalization process, it can be verified that the sample Ti/M1-P had the greatest reduction of the surface area, and this reduction was higher than $90 \%$ in relation to the sample Ti/M1.

With respect to the pore distribution curves, after the impregnation of the samples with amine, it can be observed that the pores of the samples were partially filled with amine molecules, thus confirming the reason for the decrease of the textural parameters in the samples studied, as discussed above. The same trend was also reported in studies found in the literature ${ }^{8,31,60,61}$. In addition, it was possible to verify that the materials presented a small amount of mesopores of larger sizes than the mesopores of the sample before the functionalization process. 
The hypothesis to explain this result is that the M1 sample may have presented a macroporosity that was not detected, since this porosity was outside the limit of detection of the equipment used. Suppose, then, that the amine molecules first filled up the pores of smaller size, pores detected and that appeared in the pore distribution curves, and soon afterwards, the rest of the molecules probably filled partially the macropores and/or was deposited on the surface of the material. In this way, the amine impregnated materials presented pores of larger size than their respective samples before the functionalization process, due to the decrease of the size of the macropores, as a result of filling them with the amine molecules.

\subsubsection{TG/DTG}

The TG/DTG curves obtained for the pure silica sample M1 and samples with heteroatoms, all functionalized with PEHA, are shown in Fig. 11. The presence of two regions of mass losses is verified in all samples functionalized with PEHA, and the second mass loss region is attributed to the PEHA decomposition ${ }^{62}$. In this case, the first loss of mass occurs at about $100{ }^{\circ} \mathrm{C}$ and may be associated with the water exit from the material. The profiles found for the PEHA functionalized samples are analogous to those reported by other researches ${ }^{42,62}$.

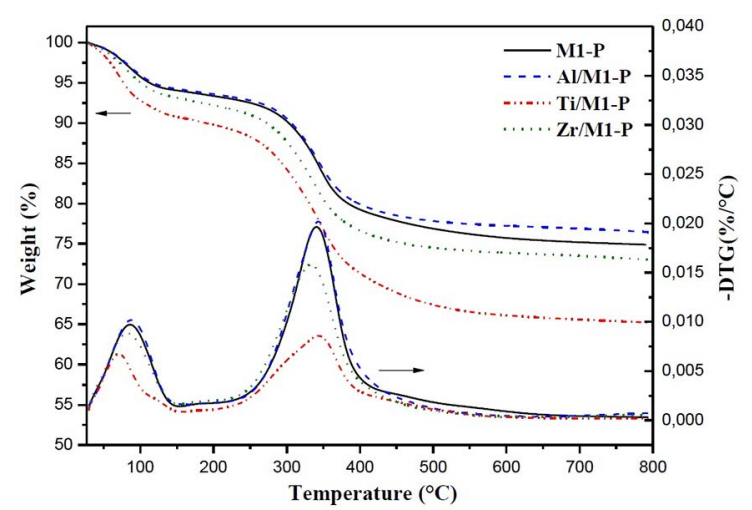

Figure 11. TG/DTG curves of the samples M1-P, Al/M1-P, Ti/M1-P and $\mathrm{Zr} / \mathrm{M} 1-\mathrm{P}$.

The thermogravimetric analysis is able to estimate the amount of amine impregnated in each sample, since the amount of amine load after the functionalization can be obtained through mass loss ${ }^{42}$. From the TG analysis, it was possible to confirm the amine load, with the percentage loss of mass of $17.3 \%, 16.0 \%, 23.1 \%$ and $17.8 \%$ for the samples M1-P, Al/M1-P, Ti/M1-P and Zr/M1-P, respectively. It is noted that the mass losses presented by the samples are less than the amount of amine added to the solution used for functionalization, thus suggesting that some amount of the compound remained in solution. The values estimated by Equation 1 for the amine content of the functionalized samples studied can be seen in Table 1. It is important to notice that sample Ti/M1-P showed the highest amine insertion.

\subsubsection{Performance evaluation}

Fig. 12 shows the $\mathrm{CO}_{2}$ adsorption curves at $30^{\circ} \mathrm{C}$ for the PEHA-functionalized samples. According to the cycles presented in the cited figures, it can be seen that the shapes of the adsorption and desorption curves for the functionalized samples are similar and that the impregnation of amines in the materials had a positive impact on the adsorption. As can be seen, adsorption and desorption curves are more pronounced in the materials incorporated with heteroatoms and functionalized with amines compared to the functionalized and non-functionalized material M1. The $\mathrm{CO}_{2}$ adsorption kinetics of the functionalized samples prepared in this work is similar to that reported for some adsorbents present in the literature ${ }^{34,63}$.

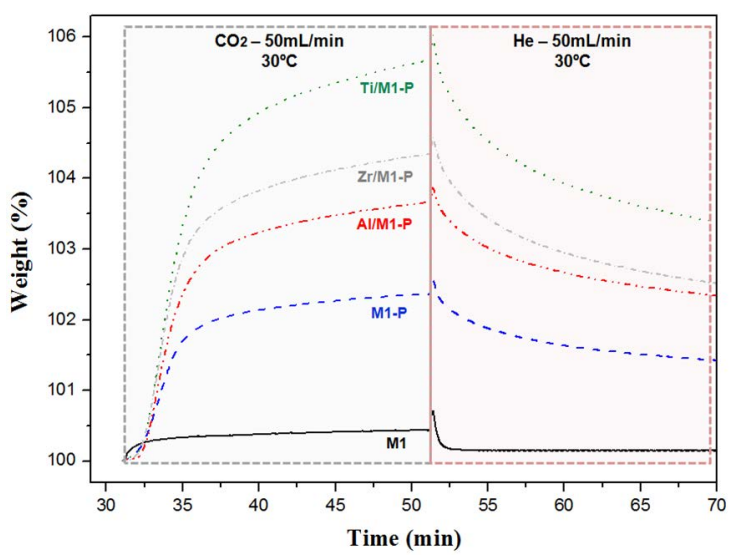

Figure 12. $\mathrm{CO}_{2}$ adsorption cycles of samples M1, M1-P, Al/M1-P, Ti/M1-P and Zr/M1-P.

Table 1 shows the values for the adsorption capacity of PEHA-functionalized materials. It is found that the $\mathrm{CO}_{2}$ adsorption capacity of the sample M1 had a significant increase after addition of heteroatoms and, subsequently, with amine functionalization. The results showed that Ti/M1-P exhibited the highest adsorption capacity $(56.9 \mathrm{mg} / \mathrm{g}$ ) among the other samples, with an increase of approximately $675 \%$ in relation to Ti/M1. For a better visualization of the performance of all the synthesized materials, a bar chart was constructed, which can be observed in Fig. 13. In this chart, it is possible to observe the significant contributions of the heteroatom and amine functionalizations to the adsorption capacity of the resulting materials, both when used separately and combined.

In view of the obtained results, it could be noticed that the incorporation of heteroatoms modified the surfaces of the materials. One hypothesis to explain this alteration of the surface of the samples is the creation of Lewis and Brønsted acid sites ${ }^{64}$. The substitution of silicon by the $\mathrm{Al}^{3+}$ ion in the silica-based samples, for instance, leads to the formation of stronger Brønsted acid sites on the surface, since the difference between $\mathrm{Si}$ and $\mathrm{Al}$ atoms is balanced by protonation of an $\mathrm{O}$ atom, after each substitution ${ }^{34,64}$. 


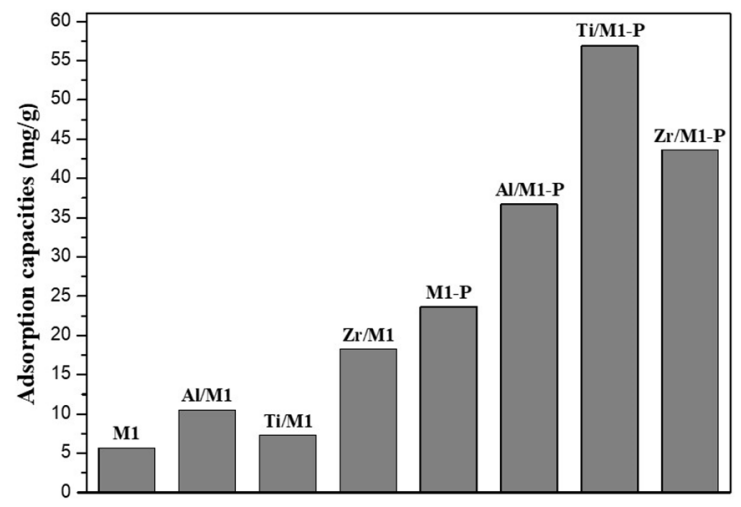

Figure 13. Adsorption capacities of all materials synthesized in this work.

According to Perez-Beltran et al. ${ }^{64}$, changes caused by aluminum do not imply major changes in the acid properties of the silanol groups initially present on the surface of the samples. On the other hand, the surface acidity properties are improved by the isomorphic substitution of $\mathrm{Ti}$ and $\mathrm{Zr}^{64}$. This is because the replacement of silicon with tetravalent ions, $\mathrm{Zr}^{4+}$ and $\mathrm{Ti}^{4+}$, results in the formation of acidic Lewis sites which, in turn, are more efficient at retaining amines than the Brønsted acid sites ${ }^{34}$. In the $\mathrm{Zr}$ insertion mainly Lewis acids sites are formed, but there are also traces of weak Brønsted acid sites. In the incorporation of Ti, only weak Lewis acid sites are produced. The acid-base interaction between the amines and the Lewis acid sites can stabilize or modify the structure of the amines, increasing the amine access to the available $\mathrm{CO}_{2}$ and, therefore, a greater amount of $\mathrm{CO}_{2}$ can be captured. In contrast, an inefficient interaction may be a consequence of the contact of the amines with the Brønsted acid sites, which in turn, will not corroborate with the capture of a large number of $\mathrm{CO}_{2}$ molecules ${ }^{34}$.

In this way, it can be said that the lower adsorption capacity obtained for the starting sample occurred because of the poor interaction between the $\mathrm{CO}_{2}$ and the adsorbent material, and as verified from the results, the incorporation of the heteroatoms and the functionalization of the amine strengthened these interactions, which reverberated positively in high adsorption capacities. The $\mathrm{CO}_{2}$ adsorption capacity for samples incorporated with heteroatoms and functionalized with amines at $30^{\circ} \mathrm{C}$ under atmospheric pressure increases in the order of: $\mathrm{Al} / \mathrm{M} 1-\mathrm{P}<\mathrm{Zr} / \mathrm{M} 1-\mathrm{P}<\mathrm{Ti} / \mathrm{M} 1-\mathrm{P}$.

Concomitantly, and aiming to associate the results referring to the performance of $\mathrm{CO}_{2}$ adsorption capacity with the results obtained by textural analysis for the materials incorporated with heteroatoms, it is possible to verify that the sample with an increase in the pore volume after the addition of heteroatoms (Ti/M1) showed the highest adsorption capacity, since the increase in the pore volume allowed a higher loading of amine in the material. Results similar to these were also obtained by $\mathrm{Xu}$ et al. ${ }^{31}$ in the studies on aluminum-incorporated material MCM-41, where the $\mathrm{CO}_{2}$ adsorption capacity for
Al-MCM-41 material was $7.6 \mathrm{mg} / \mathrm{g}$ and for Al-MCM-41 material impregnated with PEI, the adsorption capacity increased considerably, and the value obtained was $127 \mathrm{mg} / \mathrm{g}$. The authors demonstrated that when aluminum is incorporated into the structure of the MCM-41, the pore volume increases, thus allowing a larger amount of PEI to be loaded into the channels of the material MCM-41 and thus significantly improving the performance of the resulting material ${ }^{31}$.

In order to better evaluate the results, the performance analysis was repeated for the samples that presented the best $\mathrm{CO}_{2}$ adsorption performances (Ti/M1-P and Zr/M1-P), using longer cycles (of about $120 \mathrm{~min}$ for adsorption and desorption) as can be seen in Fig.14. From this figure one can find the $\mathrm{CO}_{2}$ adsorption capacity values for the samples $\mathrm{Ti} /$ M1-P and Zr/M1-P, which were $111.3 \mathrm{mg} / \mathrm{g}$ and $68.7 \mathrm{mg} / \mathrm{g}$, respectively. It can be seen, from the results obtained, that the adsorption contact time initially used was not sufficient for the samples to reach their maximum adsorption capacity. It is possible to verify that the samples Ti/M1-P and $\mathrm{Zr}$ / M1-P presented increases of approximately $96 \%$ and $58 \%$, respectively, in relation to the adsorption tests of the same samples performed in shorter cycles. Based on these results, it can be said that the samples subjected to longer adsorption cycles showed more satisfactory results in good agreement with the values for the $\mathrm{CO}_{2}$ adsorption capacities reported in the literature ${ }^{42,58,62,65}$ for adsorbents similar to those synthesized in this work, although the conditions used in the experiments were different.

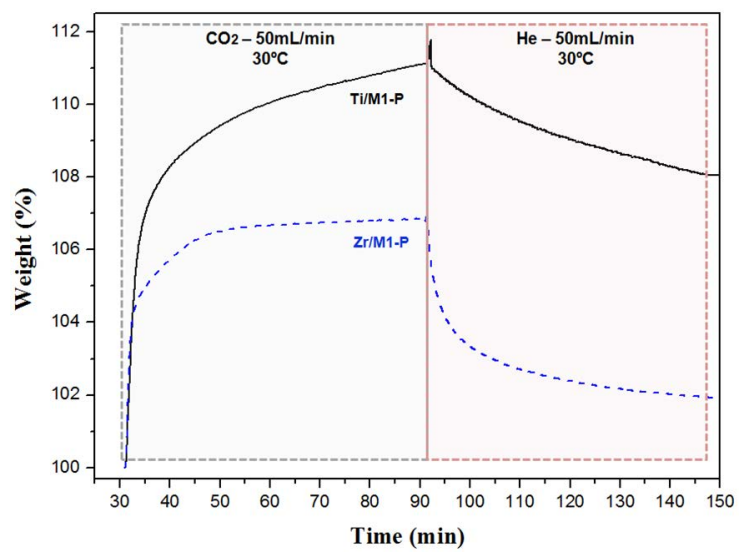

Figure 14. $\mathrm{CO}_{2}$ adsorption cycles of samples Ti/M1-P and Zr/M1-P.

In this work, it was verified that the addition of heteroatoms and functionalization contributed to obtain satisfactory results regarding the $\mathrm{CO}_{2}$ adsorption capacity of the samples studied. The positive effect of the abovementioned procedures is not fully understood by the scientific community. However, it is believed that the heteroatoms inserted in the material may have originated an amphoteric surface, capable of stabilizing the amine PEHA via acid-base interactions, and thus allowing a greater number of amine adsorption sites to be formed ${ }^{34}$. 
Consequently, the $\mathrm{CO}_{2}$ molecules became more accessible to the active sites present in the materials, thus providing a better performance of the materials, as well as adsorption/ desorption kinetics and regenerability improved, as discussed by Kuwahara et al. ${ }^{34}$.

\section{Conclusions}

In the present work, mesoporous silica monoliths were prepared by the sol-gel method. These monoliths were successfully synthesized and functionalized with different heteroatoms, exhibiting high surface areas (up to $1387 \mathrm{~m}^{2} / \mathrm{g}$ for the Ti/ M1 sample) and improvements of $220 \%(\mathrm{Zr} / \mathrm{M} 1)$ in the $\mathrm{CO}_{2}$ adosrption capacity when compared to the pure silica monolith.

The functionalization of these materials with PEHA was carried out through wet impregnation. Their $\mathrm{CO}_{2}$ adsorption capacity was greatly improved after this modification. The sample Ti/M1-P presented the highest $\mathrm{CO}_{2}$ adsorption capacity among the materials studied, reaching up to $111.3 \mathrm{mg} / \mathrm{g}$. This value is about fifteen times greater than the capacity of the Ti/M1 material and twenty times greater than the capacity of the pure silica monolith.

The insertion of heteroatoms was found to greatly benefit the $\mathrm{CO}_{2}$ adsorption properties of the monoliths, both before and after the amine functionalization. The presence of heteroatoms formed an amphoteric surface that resulted in a stronger attraction of the $\mathrm{CO}_{2}$ molecules for the aminefree materials. For the amine-functionalized adsorbents, these sites were capable of stabilizing the PEHA through acid-base interactions, thus enabling the amine to have a greater amount of adsorption sites.

Therefore, it can be said that the adsorbents in the form of monolith synthesized in this work are promising materials to be applied in the $\mathrm{CO}_{2}$ adsorption of several industrial gas streams in the CCS technology.

\section{Acknowledgements}

The authors gratefully acknowledge financial support from CAPES. Moreover, thanks for the Center of Microscopy at the Federal University of Minas Gerais for providing the equipment and technical support for experiments involving electron microscopy and thanks for the XRD laboratory of the Metallurgical Engineering Department at Federal University of Minas Gerais.

\section{References}

1 Pachauri RK, Meyer L; The Core Writing Team. Climate Change 2014: Synthesis Report. Contribution of working groups I, II and III to the fifth assessment report of the Intergovernmental Panel on Climate Change (IPCC). Geneva: IPCC; 2014.

2 Bui M, Adjiman CS, Bardow A, Anthony EJ, Boston A, Brown $\mathrm{S}$, et al. Carbon capture and storage (CCS): The way forward. Energy \& Environmental Science. 2018;11(5):1062-1176.
3 Oliveira TG. Desenvolvimento de peneiras moleculares mesoporosas do tipo MCM-41 e MCM-48 impregnadas com aminas para utilização na adsorção de $\mathrm{CO}_{2}$. [Dissertation]. São Cristóvão: Federal University of Sergipe; 2012.

4 Abu-Zahra MRM, Schneiders LHJ, Niederer JPM, Feron PHM, Versteeg GF. $\mathrm{CO}_{2}$ capture from power plants: Part I. A parametric study of the technical performance based on monoethanolamine. International Journal of Greenhouse Gas Control. 2007;1(1):37-46.

5 Singh J, Bhunia H, Basu S. Synthesis of sulphur enriched carbon monoliths for dynamic $\mathrm{CO}_{2}$ capture. Chemical Engineering Journal. 2019;374:1-9.

6 Kong Y, Shen X, Cui S, Fan M. Development of monolithic adsorbent via polymeric sol-gel process for low-concentration $\mathrm{CO}_{2}$ capture. Applied Energy. 2015;147:308-317.

7 Zohdi S, Anbia M, Salehi S. Improved $\mathrm{CO}_{2}$ adsorption capacity and $\mathrm{CO}_{2} / \mathrm{CH}_{4}$ and $\mathrm{CO}_{2} / \mathrm{N}_{2}$ selectivity in novel hollow silica particles by modification with multi-walled carbon nanotubes containing amine groups. Polyhedron. 2019;166:175-185.

8 Silva EG. Adsorção de $\mathrm{CO}_{2}$ utilizando material mesoporoso impregnado com amina. [Course Complexion Paper]. Natal: Federal University of Rio Grande do Norte; 2015.

9 Boukoussa B, Hakiki A, Bouazizi N, Beltrao-Nunes AP, Launay F, Pailleret A, et al. Mesoporous silica supported amine and amine-copper complex for $\mathrm{CO}_{2}$ adsorption: Detailed reaction mechanism of hydrophilic character and $\mathrm{CO}_{2}$ retention. Journal of Molecular Structure. 2019;1191:175-182.

10 Kim JM, Stucky GD. Synthesis of highly ordered mesoporous silica materials using sodium silicate and amphiphilic block copolymers. Chemical Communications. 2000;13:1159-1160.

11 Flodström K, Wennerström H, Teixeira CV, Amenitsch $\mathrm{H}$, Lindén M, Alfredsson V. Time-resolved in situ studies of the formation of cubic mesoporous silica formed with triblock copolymers. Langmuir. 2004;20(23):10311-10316.

12 Miyata H, Suzuki T, Fukuoka A, Sawada T, Watanabe M, Noma T, et al. Silica films with a single-crystaline mesoporous structure. Nature Materials. 2004;3:651-656.

13 Tolbert SH, Schäffer TE, Feng J, Hansma PK, Stucky GD. A New Phase of Oriented Mesoporous Silicate Thin Films. Chemistry of Materials. 1997;9(9):1962-1967.

14 Yang P, Zhao D, Chmelka BF, Stucky GD. Triblock-CopolymerDirected Syntheses of Large-Pore Mesoporous Silica Fibers. Chemistry of Materials. 1998;10(8):2033-2036.

15 Marlow F, Spliethoff B, Tesche B, Zhao D. The Internal Architecture of Mesoporous Silica Fibers. Advanced Materials. 2000;12(13):961-965.

16 Lei JH, Liu D, Guo LP, Yan XM, Tong H. Fabrication and characterization of hexagonal mesoporous silica monolith via post-synthesized hydrothermal process. Journal of Sol-Gel Science and Technology. 2006;39(2):169-174.

$17 \mathrm{Xu}$ LY, Shi ZG, Feng YQ. A facile route to a silica monolith with ordered mesopores and tunable through pores by using hydrophilic urea formaldehyde resin as a template. Microporous and Mesoporous Materials. 2007;98(1-3):303-308. 
18 Postnova IV, Chen LJ, Shchipunov YA. Synthesis of monolithic mesoporous silica with a regular structure (SBA-15) and macropores in neutral aqueous solution at room temperature. Colloid Journal. 2013;75(2):231-233.

19 El-Safty SA, Hanaoka T, Mizukami F. Large-Scale Design of Cubic Ia3d Mesoporous Silica Monoliths with High Order, Controlled Pores, and Hydrothermal Stability. Advanced Materials. 2005;17(1):47-53.

20 Melosh NA, Davidson P, Chmelka BF. Monolith Mesophase Silica with Large Ordering Domains. Journal of the American Chemical Society. 2000;122(5):823-829.

21 Yang H, Shi Q, Tian B, Xie S, Zhang F, Yan Y, et al. A Fast Way for Preparing Crack-Free Mesostructured Silica Monolith. Chemistry of Materials. 2003;15(2):536-541.

22 Huesing N, Raab C, Torma V, Roig A, Peterlik H. Periodically Mesostructured Silica Monoliths from Diol-Modified Silanes. Chemistry of Materials. 2003;15(14):2690-2692.

23 Brandhuber D, Huesing N, Raab CK, Torma V, Peterlik H. Cellular mesoscopically organized silica monoliths with tailored surface chemistry by one-step drying/extraction/ surface modification processes. Journal of Materials Chemistry. 2005;15(18):1801-1806.

24 Amatani T, Nakanishi K, Hirao K, Kodaira T. Monolithic Periodic Mesoporous Silica with Well-Defined Macropores. Chemistry of Materials. 2005;17(8):2114-2119.

25 Shi ZG, Feng YQ, Xu L, Da SL, Ren YY. Synthesis of a silica monolith with textural pores and ordered mesopores. Microporous and Mesoporous Materials. 2004;68(1-3):55-59.

26 Kajihara K. Recent advances in sol-gel synthesis of monolithic silica and silica-based glasses. Journal of Asian Ceramic Societies. 2013;1(2):121-133.

27 Clavier CW, Rodman DL, Sinski JF, Allain LR, Im HJ, Yang Y, et al. A method for the preparation of transparent mesoporous silica sol-gel monoliths containing grafted organic functional groups. Journal of Materials Chemistry. 2005; 15(24):2356-2361.

28 Otálora JAB. Otimização da sintese in situ de fases estacionárias monolíticas baseadas em sílica para uso em colunas capilares. [Dissertation]. Campinas: Campinas State University (UNICAMP); 2015.

29 Feinle A, Elsaesser MS, Hüsing N. Sol-gel synthesis of monolithic materials with hierarchical porosity. Chemical Society Reviews. 2016;45(12):3377-3399.

30 Zhong H, Zhu G, Wang P, Liu J, Yang J, Yang Q. Direct synthesis of hierarchical monolithic silica for high performance liquid chromatography. Journal of Chromatography A. 2008;1190(12):232-240.

31 Xu X, Song C, Andrésen JM, Miller BG, Scaroni AW. Preparation and characterization of novel $\mathrm{CO}_{2}$ "molecular basket" adsorbents based on polymer-modified mesoporous molecular sieve MCM-41. Microporous and Mesoporous Materials. 2003;62(1-2):29-45.

32 Franco RLM. Desenvolvimento de catalisadores de óxidos de metais de transição suportados em MCM-41 para a dessulfurização oxidativa de dibenzotiofeno. [Thesis]. São Cristóvão: Federal University of Sergipe; 2013.
33 Castelo Branco EHB. Craqueamento termocatalítico de óleo de babaçu sobre materiais nanoestruturados do tipo AlSBA-15. In: Congresso Internacional das Licenciaturas - COINTER PDVL 2015; 2015 Dec 1-3; Recife, PE, Brazil.

34 Kuwahara Y, Kang DY, Copeland JR, Bollini P, Sievers C, Kaegawa $\mathrm{T}$, et al. Enhanced $\mathrm{CO}_{2}$ Adsorption over Polymeric Amines Supported on Heteroatom-incorporated SBA-15 Silica: Impact of Heteroatom Type and Loading on Sorbent Structure and Adsorption Performance. Chemistry - A European Journal. 2012;18(52):16649-16664.

35 Choi S, Gray ML, Jones CW. Amine-Tethered Solid Adsorbents Coupling High Adsorption Capacity and Regenerability for $\mathrm{CO}_{2}$ Capture From Ambient Air. ChemSusChem. 2011;4(5):628-635.

36 Liu X, Zhou L, Fu X, Sun Y, Su W, Zhou Y. Adsorption and regeneration study of the mesoporous adsorbent SBA-15 adapted to the capture/separation of $\mathrm{CO}_{2}$ and $\mathrm{CH}_{4}$. Chemical Engineering Science. 2007;62(4):1101-1110.

37 Chen C, Yang ST, Ahn WS, Ryoo R. Amine-impregnated silica monolith with a hierarchical pore structure: enhancement of $\mathrm{CO}_{2}$ capture capacity. Chemical Communications. 2009;24:3627-3629.

38 Kim J, Desch RJ, Thiel SW, Guliants VV, Pinto NG. Energetics of protein adsorption on amine-functionalized mesostructured cellular foam silica. Journal of Chromatography A. 2001;1218(43):7796-7803.

39 Ribeiro JON. Synthesis, characterization and performance evaluation of mesoporous silica functionalized with amine for adsorption of $\mathrm{CO}_{2}$ from natural gas. [Dissertation]. Belo Horizonte: Federal University of Minas Gerais; 2016.

40 Barbosa MN. Sintese, caracterização e aplicação de MCM-41 funcionalizado com di-isopropilamina no processo de adsorção do dióxido de carbono. [Dissertation]. Natal: Federal University of Rio Grande do Norte; 2009.

41 Alves JABLR. Sintese e caracterização da peneira molecular MCM-41 contendo terras raras na dessulfurização, utilizando tiofeno como molécula sonda. [Dissertation]. Natal: Federal University of Rio Grande do Norte; 2010.

42 Liu Z, Teng Y, Zhang K, Chen $\mathrm{H}$, Yang Y. $\mathrm{CO}_{2}$ adsorption performance of different amine-based siliceous MCM-41 materials. Journal of Energy Chemistry. 2015;24(3):322-330.

43 Brito HG, Vale JRL. Incorporação de grupos funcionais em matrizes de sílica mesoporosa do tipo SBA-15: investigação das condições de síntese e aplicação. In: I Congresso Nacional de Engenharia de Petróleo, Gás Natural e Biocombustíveis; 2015 May 13-15; Campina Grande, PB, Brazil.

44 Xie Y, Zhang Y, Ouyang J, Yang H. Mesoporous material AlMCM-41 from natural halloysite. Physics and Chemistry of Minerals. 2014;41(7):497-503.

45 Castro KKV. Síntese, caracterização e aplicação do MCM-41 e Al-MCM-41 na pirólise do resíduo atmosférico de petróleo. [Dissertation]. Natal: Federal University of Rio Grande do Norte; 2009.

46 Sing KSW, Everett DH, Haul RAW, Moscou L, Pierotti RA, Rouquérol J, et al. Reporting Physisorption Data for Gas/Solid Systems With Special Reference to the Determination of Surface Area and Porosity. Pure and Applied Chemistry. 1985;57:603-619. 
47 Groen JC, Peffer LAA, Pérez-Ramírez J. Pore size determination in modified micro- and mesoporous materials. Pitfalls and limitations in gas adsorption data analysis. Microporous and Mesoporous Materials. 2003;60(1-3):1-17.

48 Zhang Y, Shao D, Yan J, Jia X, Li Y, Yu P, et al. The pore size distribution and its relationship with shale gas capacity in organic-rich mudstone of Wufeng-Longmaxi Formations, Sichuan Basin, China. Journal of Natural Gas Geoscience. 2016;1(3):213-220.

49 Thielemann JP, Girgsdies F, Schlögl R, Hess C. Pore structure and surface area of silica SBA-15: influence of washing and scale-up. Beilstein Journal of Nanotechnology. 2011;2:110-118.

50 van Der Voort P, Ravikovitch PI, De Jong KP, Neimark AV, Jansen AH, Benjelloun M, et al. Plugged hexagonal mesoporous templated silica: A unique micro- and mesoporous material with internal silica nanocapsules. Chemical Communications. 2002;9:1010-1011.

51 Wei J, Liao L, Xiao Y, Zhang P, Shi Y. Capture of carbon dioxide by amine-impregnated as-synthesized MCM-41. Journal of Environmental Sciences. 2010;22(10):1558-1563.

52 Mello MR, Phanon D, Silveira GQ, Llewellyn PL, Ronconi CM. Amine-modified MCM-41 mesoporous silica for carbon dioxide capture. Microporous and Mesoporous Materials. 2011;143(1):174-179.

53 Silva MLP. Sintese e caracterização de peneiras moleculares mesoporosas do tipo MCM-41 e AlMCM-41 a partir de fontes alternativas de sílica e de alumínio. [Thesis]. Natal: Federal University of Rio Grande do Norte; 2009.

54 Silva FMN, Carvalho WMNC, Cabral RPB. Preparação e caracterização de aluminosilicato mesoporoso Al-MCM-41 para aplicação no refino de petróleo. In: $1^{\circ}$ Encontro Nacional de Educação, Ciência e Tecnologia-ENECT; 2012 Nov 11-14; Campina Grande, PB, Brazil. 10 p.

55 Ji C, Huang X, Li L, Xiao F, Zhao N, Wei W. PentaethylenehexamineLoaded Hierarchically Porous Silica for $\mathrm{CO}_{2}$ Adsorption. Materials (Basel). 2016;9(10):835.
56 Fabiano TA, Soares VP, Andreoli E. Pentaethylenehexamine- $\mathrm{C}_{60}$ for Temperature Consistent Carbon Capture. Journal of Carbon Research. 2015;1(1):16-26.

57 Vunain E, Opembe NN, Jalama K, Mishra AK, Meijboom R. Thermal stability of amine-functionalized MCM-41 in different atmospheres. Journal of Thermal Analysis and Calorimetry. 2014;115(2):1487-1496.

58 Barbosa MN. Estudo de materiais mesoporosos funcionalizados com diferentes aminas para captura do dióxido de carbono através do processo de adsorção. [Thesis]. Natal: Federal University of Rio Grande do Norte; 2013.

59 Wei L, Gao Z, Jing Y, Wang Y. Adsorption of $\mathrm{CO}_{2}$ from Simulated Flue Gas on Pentaethylenehexamineloaded Mesoporous Silica Support Adsorbent. Industrial \& Engineering Chemistry Research. 2013;52(42):14965-14974.

60 de Carvalho LS, Silva E, Andrade JC, Silva JA, Urbina M, Nascimento PF, et al. Low-cost mesoporous adsorbents aminesimpregnated for $\mathrm{CO}_{2}$ capture. Adsorption. 2015;21(8):597-609.

61 Martín CF, Sweatman MB, Brandani S, Fan X. Wet impregnation of a commercial low cost silica using DETA for a fast post-combustion $\mathrm{CO}_{2}$ capture process. Applied Energy. 2016;183:1705-1721.

62 Wei L, Jing Y, Gao Z, Wang Y. Development of a pentaethylenehexamine-modified solid support adsorbent for $\mathrm{CO}_{2}$ capture from model flue gas. Chinese Journal of Chemical Engineering. 2015;23(2):366-371.

63 Li Y, Sun N, Li L, Zhao N, Xiao F, Wei W, et al. Grafting of Amines on Ethanol-Extracted SBA-15 for $\mathrm{CO}_{2}$ Adsorption. Materials (Basel). 2013;6:981-999.

64 Perez-Beltran S, Balbuena PB, Ramírez-Caballero GE. Surface Structure and Acidity Properties of Mesoporous Silica SBA-15 Modified with Aluminum and Titanium: FirstPrinciples Calculations. The Journal of Physical Chemistry C. 2016;120(32):18105-18114.

65 Son WJ, Choi JS, Ahn WS. Adsorptive removal of carbon dioxide using polyethyleneimine-loaded mesoporous silica materials. Microporous and Mesoporous Materials. 2008;113(1-3):31-40. 